\title{
Development of Incubator Analyzer Based on Computer with Temperature And Humidity Parameter
}

\author{
Syarifatul Ainiyah ${ }^{1}$, Dwi Herry Andayani ${ }^{1}$, Andjar Pudji ${ }^{1}$, Triwiyanto ${ }^{1}$, M. Shaib ${ }^{2}$ \\ ${ }^{1}$ Department of Electromedical Engineering Poltekkes Kemenkes, Surabaya \\ Jl. Pucang Jajar Timur No. 10, Surabaya, 60282, Indonesia \\ ${ }^{2}$ Departments of Biomedical and Electrical Engineering, Lebanese International University, Lebanon
}

\begin{abstract}
Article Info
Article History:

Received Sep 9, 2019

Revised May 20, 2020

Accepted Jun 11, 2020

Abstract

By opening and closing an infant incubator window during calibration, it can cause temperature leaks, such as a decrease in the incubator temperature. The purpose of this study is to develop an incubator analyzer, in which the data can be recorded to a computer for temperature and humidity parameters based on Bluetooth communication. Whereas for a non-computer displayed, the information is shown on a 20x4 LCD with SD Card storage. The contribution of this study is to calibrate baby incubators without a decrease in temperature, and also, the system can monitor the

Keywords: data collection at a maximum distance of 10 meters. In order to avoid decreasing in temperature, the module is displayed on the Personal Computer and storage on the SD Card. Incubator Analyzer is

Incubator Analyzer;

Humidity;

Temperature; Shown

$\mathrm{PC}$ and Non PC. designed to simplify and facilitate calibration with temperature parameters at 5 points using a DS18B20 sensor, mat temperature using a $K$ type thermocouple and humidity using a DHT22 sensor. In the temperature setting of $34 \mathrm{C}$ and $36 \mathrm{C}$, the average error result is $\mathbf{- 4 . 8 7 \%}$ for DS18B20, $\mathbf{- 7 . 3 9 \%}$ error for mattress temperature, and $\mathbf{- 2 4 . 8 0 \%}$ for humidity sensor. Data generated from comparisons using the INCU II test conclude that the measurement results between modules and standard devices have significant differences in values. The results of this study can be implemented on baby incubators to increase the appropriateness of the device.
\end{abstract}

\section{Corresponding Author:}

andayanidwiherry@yahoo.co.id

Department of Electromedical Engineering

Poltekkes Kemenkes, Surabaya
This work is an open-access article and licensed under a Creative Commons Attribution-ShareAlike 4.0 International License (CC BY-SA 4.0).

\section{INTRODUCTION}

Testing and calibration of medical devices are carried out to ensure their availability following service standards, quality requirements, safety, benefits, safety, and serviceability. Calibration according to Regulation of the Minister of Health Number 363/Menkes/Per/IV/1998 is an illumination activity to determine the correctness of the appointment value of the equipment measure and/or measuring material [1]. Hypothermia occurs when body temperature drops below 36.5 ${ }^{\circ} \mathrm{C}$. A newborn with a body temperature between 36.0-36.4 ${ }^{\circ}$ $\mathrm{C}$ is likely to be under cold pressure, which causes concern. Temperatures of $32.0-35.9^{\circ} \mathrm{C}$ are affected by moderate hypothermia, while temperatures below $32^{\circ} \mathrm{C}\left(89.6^{\circ} \mathrm{F}\right)$ are considered severe hypothermia. A baby gets cold soon after giving birth at a high risk of having difficulty breathing. If action is not taken immediately, then the baby will die. Infants who are not with the mother can increase the risk of prolonged hypothermia due to a lack of heat production and continued heat loss. In addition, there is a higher risk of infection and cold injury. Prolonged cold injuries, one of which causes general bleeding (especially lung bleeding) [2]. According to the American Academy of Pediatrics (AAP), normal baby temperatures between $36.1-38^{\circ} \mathrm{C}$ while for relative humidity between $60 \%-65 \%$ to maintain heat loss can be prevented by convection [3]. The temperature of the environment of the newborn care area must be adjusted independently and controlled to prevent heat and cold. The air temperature must be maintained between $22-26^{\circ} \mathrm{C}\left(72-78^{\circ} \mathrm{F}\right)$ and humidity between $30 \%$ and $60 \%$ controlled and condensation on walls and window surfaces should be avoided [4] [5]. Generally, the baby incubator has a transparent, clean surface, has good air 
insulation, the temperature can be adjusted according to needs, and relative humidity as the baby in the mother's womb [3]. Some newborns who have a gestational age or underweight baby will put the baby at a high risk of death [6]. In developing countries, 20 million premature babies or babies who have low birth weight deaths occur due to unreliable baby incubators, 4 million premature babies die in the first month [5].

The incubator analyzer was previously researched by Rizka Nur Uswatun Nadziroh (in 2018) viz P.Design of Portable Incubator Analyzer Via PC with humidity parameters, noise, and airflow. ABut in this research, there is a drawback that is not yet able to do automatic data processing through Excel [7]. In the same year, a study conducted by Imro'ah Dyah Sulistya (temperature and airflow parameters) titled Portable Incubator Analyzer Equipped with Bluetooth Data Transmission. Android shows that there are deficiencies in the airflow sensor, there is a large error value and cannot be stored, print mode After measuring and processing data automatically using Excel [8]. There is 2019 further research carried out by Agistya Ananda Charisa with the title of Portable Wireless Via PC Incubator Analyzer with SD Card storage. However, the large box is so difficult when compared to the gold standard; besides that, there is also no automatic data processing through Microsoft Excel, and the data display on the SD Card is less attractive [9]. According to the results of library research through the study of A Light Weight Secured and Efficient Health Monitoring System Implemented Over IOT Based Networks measuring patient temperature using a DS18B20 sensor, the results of accurate temperature parameters and lower prices. But it still provides security for the health of patients efficiently [10]. The DHT22 sensor module has been researched under the title Design and Development of Microcontroller Based Wireless Humidity Monitor, which results in an average accuracy of around 2\% [11]. However, the DHT22 humidity sensor has the disadvantage that it takes 2 seconds per data transmission compared to the SHT11 humidity sensor, which only requires 11 milliseconds before measurement [12]. This study is based on the author's observations when performing the calibration practice on the incubator analyzer device in the Surabaya Electromedical Engineering. It is proved when the incubator door is open and close, and then it can influence the temperature, which impacts the temperature leakage, such as the temperature decrease when the door is opened. And in taking data is done manually (handwritten) on an excel worksheet and data retrieval per parameter can only be done once because it uses one small size display that allows human error.

In connection with the results of research weaknesses that have been mentioned, among others: 1.) there is no storage mode, print mode, and automatic processing in Excel, 2.) Automatic data processing cannot yet be done through Excel, 3.) Large-sized boxes, cannot Automatic data processing is done through Microsoft Excel and the data displayed on the SD Card is not attractive, 4.) calibration measurement by opening and closing the door of the baby incubator which impacts leakage on temperature, 5.) data retrieval is done manually (handwritten) on the excel worksheet, 6.) data retrieval per parameter can only be done alternately because it uses 1 small size display. So with the weaknesses in previous research, the purpose of this research is "Development of PC and Non PC Shows Incubator Analyzer Temperature and Humidity Parameters", the appearance of LCDs for Non PCs with SD card storage and the appearance of Personal Computers using Bluetooth $\mathrm{HC} 05$ to facilitate calibration activities when not using a PC can still be used through LCD with SD card storage just in case when the battery runs out. Whereas if you use a PC, data collection can be more optimal because the PC display is accompanied by a temperature graph so that it can know when the temperature is stable, and the display per parameter is displayed in real-time. The research is expected to facilitate the calibration activities. The appearance of LCD for non PC with SD card storage and appearance of Personal Computer using Bluetooth $\mathrm{HCO5}$ to facilitate the calibration activities when not using a PC can still be used through the LCD with SD card storage just in case when the battery runs out.

Whereas if you use a PC, data collection can be more optimal because the PC display is accompanied by a temperature graph so that it can know when the temperature is stable, and the display per parameter is displayed in real-time. The research is expected to facilitate the calibration activities. The appearance of LCD for non-PC with SD card storage and appearance of Personal Computer using Bluetooth HC05 to facilitate the calibration activities when not using a PC can still be used through the LCD with SD card storage just in case when the battery runs out. Whereas, if you use a PC, data collection can be more optimal because the PC display is accompanied by a temperature graph so that it can know when the temperature is stable, and the display per parameter is displayed in real-time. The research is expected to facilitate the calibration activities. Whereas, if you use a computer, data collection can be more optimal because the PC display is accompanied by a temperature graph so that it can know when the temperature is stable, and the display per parameter is displayed in real-time. The research is expected to facilitate the calibration activities. Whereas, if you use a computer data collection can be more optimal because the PC display is accompanied by a temperature graph so that it can know when the temperature is stable and the display per parameter is displayed in real-time. The research is expected to facilitate the calibration activities.

This study is composed of: Chapter II contains Material and Methods, Chapter III contains Results, Chapter IV Discussion, Chapter V contains Conclusions, Chapter VI contains Suggestions. 


\section{MATERIALS AND METHODS}

\section{A. Experimental Setup}

The Incubator Analyzer research tool uses the subject of Baby Incubator. Data retrieval is done by looking at the display on the LCD and display sensor readings that have been sent using Bluetooth HC-05 on a PC 6 times every 10 minutes. Data is collected alternately using a comparison tool in the form of INCU II.

\section{B. Materials and Device}

Incubator temperature sensor in this study using DS18B20. For the temperature of the mattress using Thermocouple sensors and DHT22 for humidity sensors. Program processing and processing using Arduino Uno. Other components used include a 4 × 20 LCD, Delphi application as programming for PC display, HC-05 Bluetooth module for sending data from Arduino to Delphi, using the SD card module as data storage, and the charger module for charging the battery.

\section{Experiment}

In this study, researchers measured the temperature values at 5 points, the temperature of the mattress, and the humidity of the baby incubator, and the results were compared with standard equipment. The block diagram is shown in Figure.1

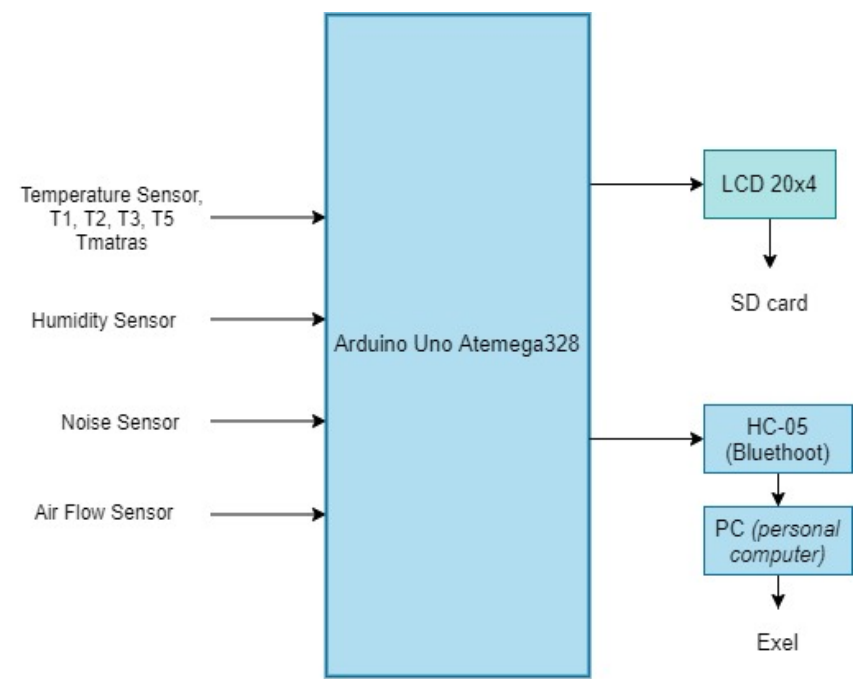

Fig. 1. The diagram block of the Incubator Analyzer Shown PC and Non PC

\section{The Diagram Block}

The on/off button functions to connect and disconnect the battery which functions as a circuit supply. When the whole series has been supplied, the temperature sensors 1, 2, 3, 4, 5, the mattress temperature, the airflow sensor, the humidity sensor, and the noise get voltage. Arduino UNO (IC Atmega 328) as a processor contains a program so that the sensors can read and display on the character LCD (as output). The save button functions for storage using an SD card and a reset button to start the program again For PC display sensor readings are taken from data processed on Arduino by sending using Bluetooth HC-05 equipped with a temperature graph display

\section{E. The Flowchart}

Initialization on the sensor will get the value data results from the reading by the temperature sensor T1 to Tmatras and humidity. When the sensor reading data has been obtained, the data will be sent using Bluetooth. The function of Bluetooth is to send the sensor reading data. If data sent using Bluetooth is sent, then the data will be displayed on a 20x4 LCD and can be stored using an SD card and can be displayed on a PC using Delphi programming to display it and can be stored in a predefined file. In the flow chart above, there is a reset button that is used to reset or delete data, to start reading as before it is done by pressing the start button. The flowchart is shown in Figure.2

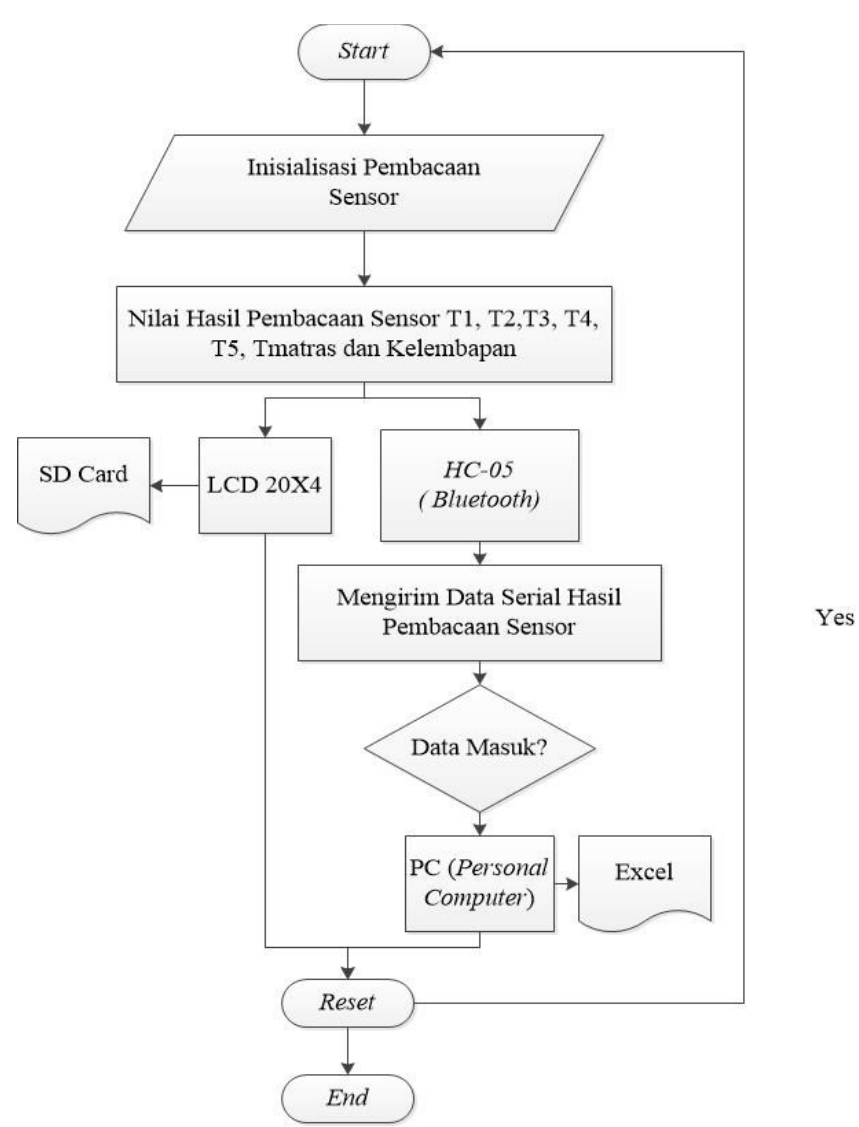

Fig. 2. The Flowchart of the Incubator Analyzer Shown PC and Non PC

\section{F. Circuit}

1) DS18B20 sensor circuit

The circuit gets an input voltage of $5 \mathrm{~V}$ and GND so that the DS18B20 temperature sensor is active and can detect the incubator room temperature. Output data from the DS18B20 temperature sensor is connected to the Arduino 
digital 6 pins which has been programmed and processed and then the results are displayed on the LCD and sent to a PC via Bluetooth HC-05 for PC appearance (Fig.3).

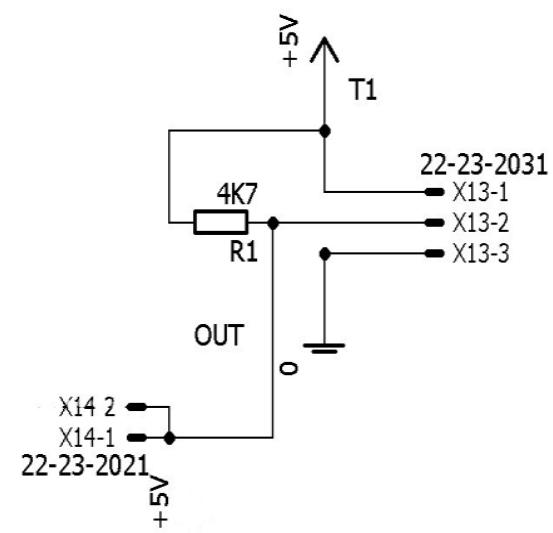

Fig. 3. DS18B20 sensor circuit

\section{2) Mattress temperature sensor circuit}

Thermocouple K type sensor (Fig.4) is a temperature sensor that is easy to use, but there are difficulties in using it because the voltage that can be measured is very small. Therefore, Max6675 (PSA) is needed as an output voltage amplifier.

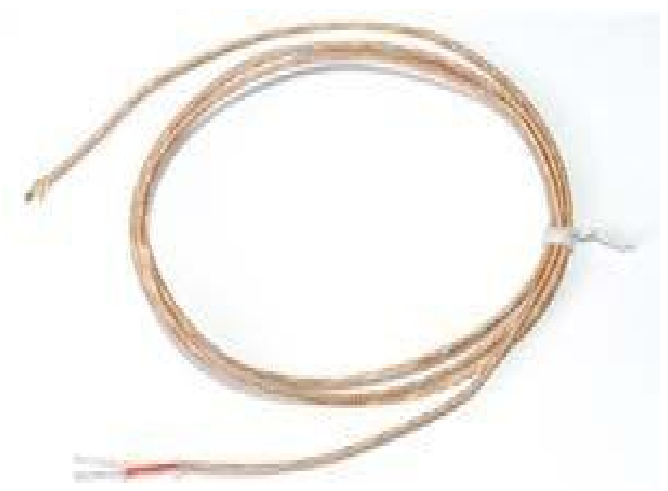

Fig. 4. Thermocouple sensor

The circuit requires a 5 volt supply voltage to ground. Besides, it connects the Max6675 pin to the Arduino pin (Fig.5). SO pins on Arduino D9 digital pins, CS pins on D8 digital pins, and SCK on D13 pins.

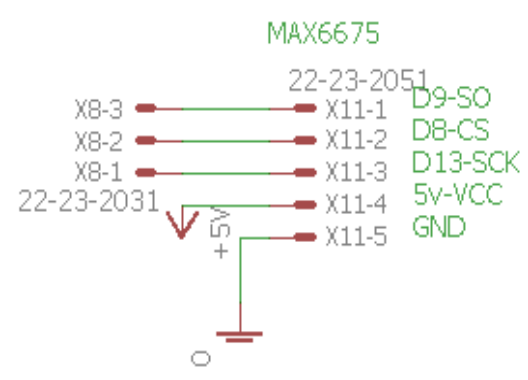

Fig. 5. MAX6675 module

\section{3) DHT22 sensor circuit}

The DHT22 humidity sensor circuit requires a gap between $5 \mathrm{~V}$ and GND (Fig.6). The humidity sensor readings have a data pin that will be connected to the Arduino pin 7.

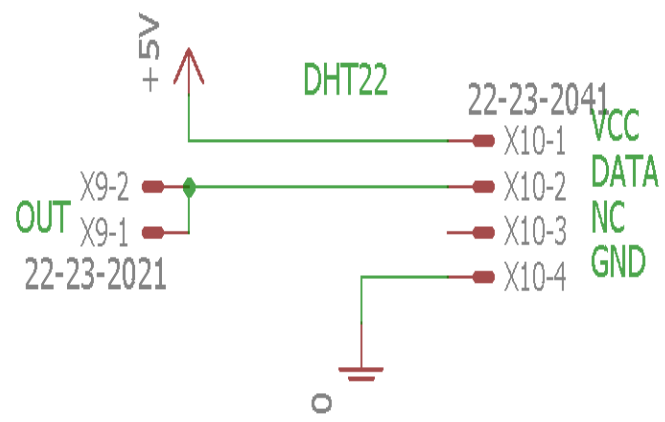

Fig. 6. DHT22 sensor circuit

\section{4) Minimum Sistem}

The Minimum System Series contains the program used for processing the output data of each sensor as well as programming the sending of data using Bluetooth $\mathrm{HC}-05$. The DS18B20 output data pin is connected to pin D6, pin D7 for the output of the DHT22 data pin, and digital Arduino pins D8, D9, D13 for MAX6675. The minimum system circuit requires an input voltage of $5 \mathrm{~V}$ and a ground sourced from the battery (Fig.7).

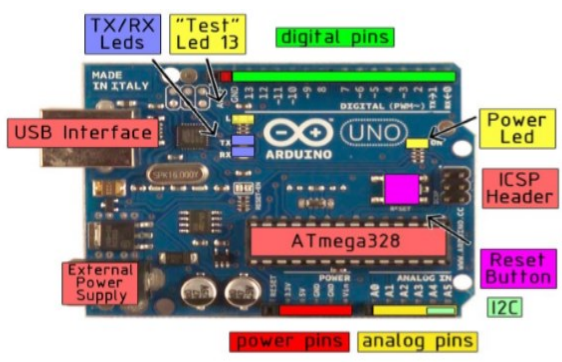

Fig. 7. Arduino Uno 


\section{5) Bluetooth module}

The HC-05 module (Fig.8) is used to send data from the sensor readings to the Delphi program for PC viewing. The Bluetooth module is connected to the Arduino Uno Microcontroller by connecting the Arduino Uno TX pin to the RX HC-05 pin and vice versa, the Arduino Uno RX pin to the TX HC-05 pin.

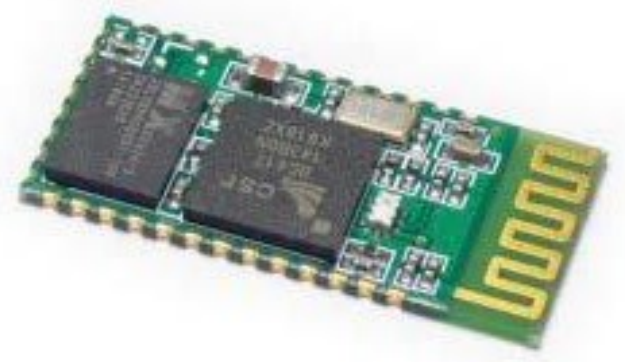

Fig. 8. Bluetooth HC-05

\section{RESULTS}

In this study, module measurements were made on the baby incubator to measure the temperature of the incubator, the temperature of the mattress, and humidity by using INCU II as a comparison tool.

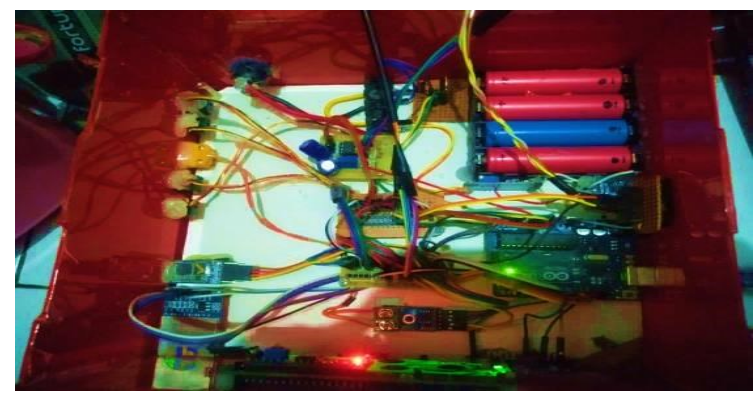

Fig. 9. Circuit Design

\section{1) Module Design}

In the design of the incubator analyzer module, there is a DS18B20 sensor circuit for Incubator temperature, Thermocouple for mattress temperature, DHT22 for humidity and noise, and airflow sensors. There are batteries for power supply throughout the circuit equipped with a charger module-Arduino Uno module as a processor and Bluetooth HC-05 for sending sensor readings to Delphi for PC display.

\section{2) Listing Program for Arduino}

The DS18B20 listing program is shown pseudocode 1. The program listing for the thermocouple mat temperature parameter is shown in pseudocode 1 , and the DHT22 humidity parameter is shown in pseudocode 2 .
Pseudocode 1: DS18B20 Temperature Program

\section{CALL OneWire.h}

CALL DallasTemperature.h

CALL ONE_WIRE_BUS 6

INIT:

OneWire oneWire(ONE_WIRE_BUS);

DallasTemperature sensors(\&oneWire);

DeviceAddress sensor $1=$

$\{0 \times 28,0 \times 20,0 \times 5 F, 0 \times 79,0 \times 97,0 \times 11,0 \times 3,0 \times F 1\}$;

unsigned char adc1, adc2;

float temp;

float data1;

int datakirim 1;

sensors.request Temperatures();

\section{LOOP:}

temp $=$ sensors.get TempC(sensor 1$)$;

data $1=$ temp +0.2 ;

datakirim $1=$ data $1 * 100$;

Serial.print("a");

adc $1=$ datakirim $1 / 100$;

adc $2=$ datakirim $1 \% 100$;

Serial.print (char(adc1));

Serial.print (char(adc2));

lcd.setCursor $(0,0)$;

lcd.print("T1:");

lcd.print(data1);

lcd.print("C");

delay (100);

\section{ENDLOOP}

The temperature program 1 on Arduino includes a program including the DS18b20 library, sensor pin initialization connected to the Arduino D6 digital pin, the address for each temperature sensor because it uses only one Arduino digital pin, sensor reading, temperature conversion 1 for transmission on Delphi and LCD. for temperature 1. For temperatures 2 to 5 the temperature of the program as above is only different variables and the location of the rows and columns of the LCD.

Pseudocode 2:. Therocouple Temperature Program

CALL include "max6675.h"
INIT
ktcSO $=8 ;$
ktcCS $=9 ;$
ktcCLK $=10 ;$
MAX6675 ktc (ktcCLK, ktcCS, ktcSO);
float tmatras;
float data6;
int datakirim6;
LOOP
tmatras $=($ ktc. readCelsius ()$) ;$
data6 =tmatras;




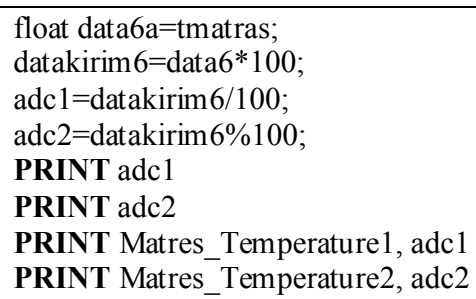

\section{ENDLOOP}

The above program is a program for mattress temperatures on Arduino in the form of programs inserting the PSA library MAX6675 module for Thermocouple voltage amplifiers, initialization of CLK, CS and SO pins connected to Arduino pins D8, D9 and D10 as well as sensor readings, mat temperature conversion for transmission in Delphi, and initialization of CLK, CS and SO pins connected to Arduino pins D8, D9 and D10, LCD for the mattress temperature according to the LCD lines and columns specified

\section{Pseudocode 3. DHT22 Program}

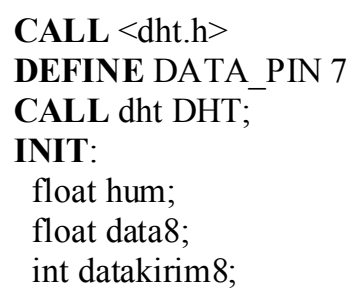

\section{LOOP:}

float readData $=$ DHT.read22(DATA_PIN);

float hum = DHT.humidity;

data8=hum-16;

float data $8 \mathrm{a}=$ hum-16; datakirim $8=$ data $8 * 100$; adc $1=$ datakirim $8 / 100$; adc2 $=$ datakirim $8 \% 100$;

PRINT adc1

PRINT adc2

PRINT HUMIDITY

\section{ENDLOOP}

The above program is a program for the humidity sensor in Arduino in the form of a program to insert the DHT22 library, initialization of the DHT22 data pin that is connected to the Arduino D7 pin and humidity sensor reading, conversion of humidity sensor reading for sending on Delphi and LCD for humidity following LCD lines and columns determined.

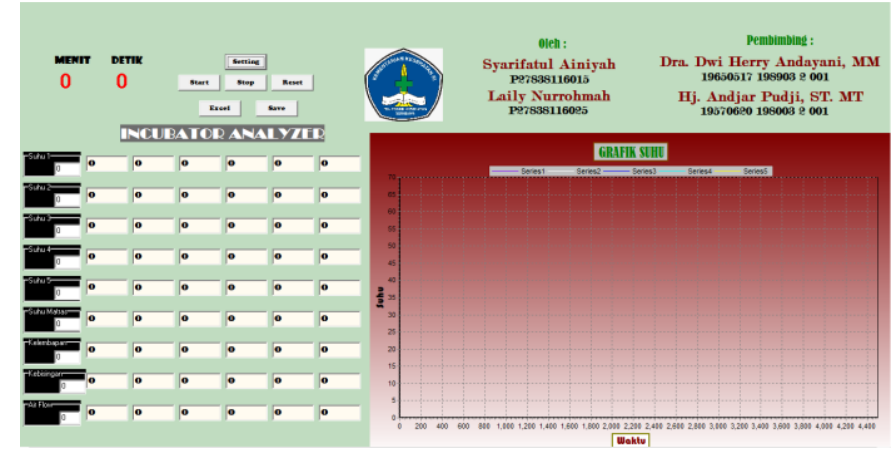

Fig. 10. Display on Delphi

Display on a PC in the form of Delphi with 6 measurements for each parameter, by sending via Bluetooth HC-05. In Bluetooth, HC-05 is installed on Arduino by connecting Arduino RX to TX HC-05 and vice versa tx Arduino to rxHC05 .

Pseudocode 4: Reading Incubator Temperature

\section{INIT:}

var tegangan1:real; data1:string;sensor 1:real;

\section{LOOP}

IF Chart1.Series[0].MaxXValue $>0$ THEN

sensor $1:=(\operatorname{Ord}(\operatorname{Str}[1]) * 100)+\operatorname{Ord}(\operatorname{Str}[2])$;

tegangan $1:=$ sensor $1 / 100$;

PRINT tegangan

data1:=edit1.Text[1];

IF (menit=10) and (detik=0) THEN edit10.Text:=(floattostr(tegangan 1$))$; data1:=edit10.Text[2];

\section{ENDIF}

PLOT tegangan1

IF Chart1.Series[0].MaxXValue >

Chart1.BottomAxis.Maximum THEN

Chart1.Series[0].Clear;

xval: $=0$;

ENDIF

ENDIF

$\mathrm{xval}:=\mathrm{xval}+1$;

ENDLOOP; 
Pseudocode 5: Delphi Program Mattress Temperature

INIT:
tegangan6:real; data6:string; sensor6:real;
LOOP:
sensor6:=(Ord(Str[11])*100)+Ord( $\operatorname{Str}[12]) ;$
tegangan6:= sensor6/100;
PRINT tegangan6
data6:=edit6.Text[1];
IF (menit=10) and (detik=0) THEN
PRINT tegangan6
ENDIF;
ENDLOOP

Pseudocode 6: Delphi Program Reading Humidity

INIT:

var tegangan8:real;data8:string;sensor8:real;

LOOP:

sensor8: $=(\operatorname{Ord}(\operatorname{Str}[15]) * 100)+\operatorname{Ord}(\operatorname{Str}[16])$;

tegangan $8:=$ sensor8/100;

PRINT tegangan 8

data8:=edit8.Text[1];

IF (menit=10) and (detik=0) THEN

PRINT tegangan8

ENDIF;

\section{ENDLOOP}

4) Error value DS18B20 and Thermocouple

a. T1-T5 error $\%$ measurement results at a temperature setting $34^{\circ} \mathrm{C}$

According to the measurement results of the comparison between modules and standard tools or INCU II at a temperature setting of $34 \mathrm{C}$ between $\mathrm{T} 1$ to $\mathrm{T} 5$, the largest percent error result is $4.42 \%$ (Fig. 11 ).

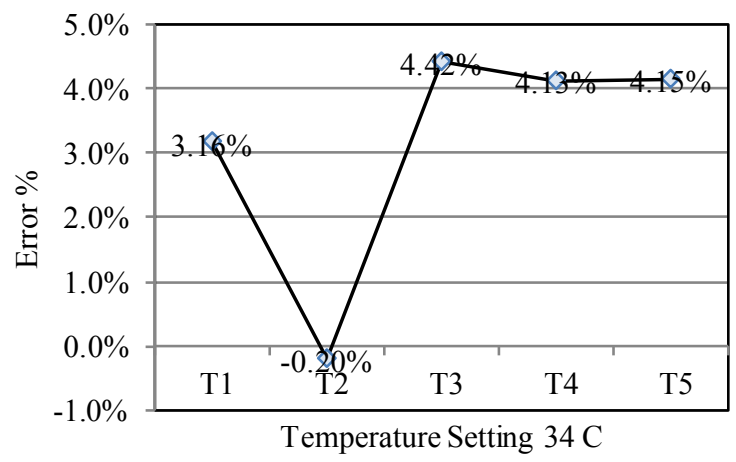

Fig. 11. Error measurement b. The measurement results of the difference between the module and INCU II at a temperature setting of $34^{\circ} \mathrm{C}$

The average result of the difference or error between the module and INCU II at temperature measurement $\mathrm{T} 1$ to $\mathrm{T} 5$ temperature setting $34 \mathrm{C}$ is $+-1.14 \mathrm{C}$ (Fig.12).

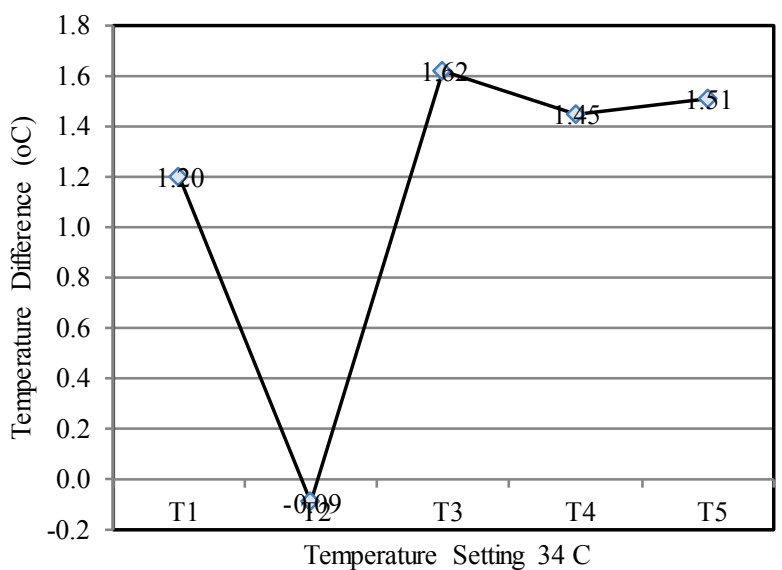

Fig. 12. The temperature difference between design and calibrator

c. Mattress error $\%$ measurement results at a temperature setting $34^{\circ} \mathrm{C}$

According to the measurement results of the comparison between modules and standard devices or INCU II temperature regulation $34 \mathrm{C}$ at the mat temperature obtained error results of $-2.21 \%$. As for the difference or error between the module and INCU II on the measurement of the $34 \mathrm{C}$ mat temperature the temperature setting is $+-0.77 \mathrm{C}$ (Fig.13).

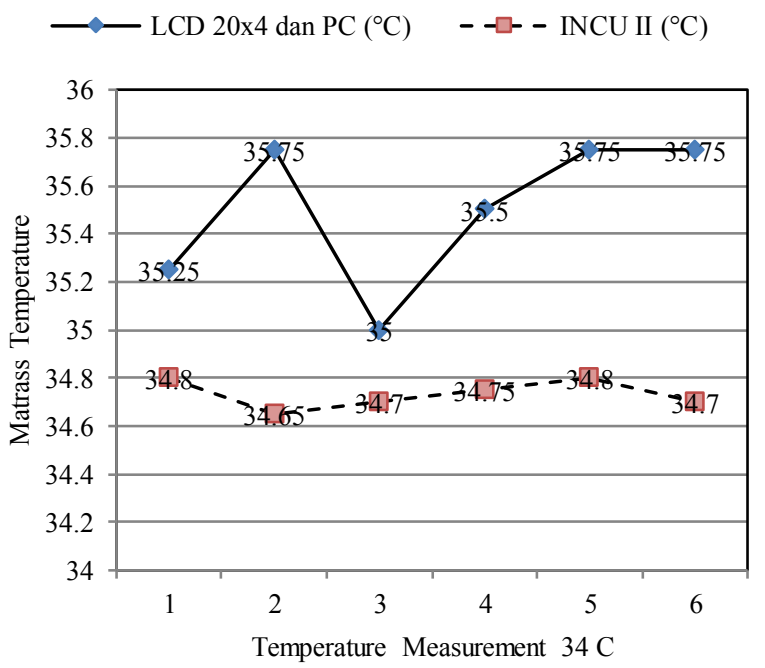

Fig. 13. Temperature measurement for six-time 
d. T1-T5 measurement results at a temperature setting $36^{\circ}$ C.

According to the measurement results of the comparison between modules and standard devices or INCU II at a temperature setting of $36 \mathrm{C}$ between $\mathrm{T} 1$ to $\mathrm{T} 5$, the largest percent error results obtained $-4.87 \%$ (Fig.14).

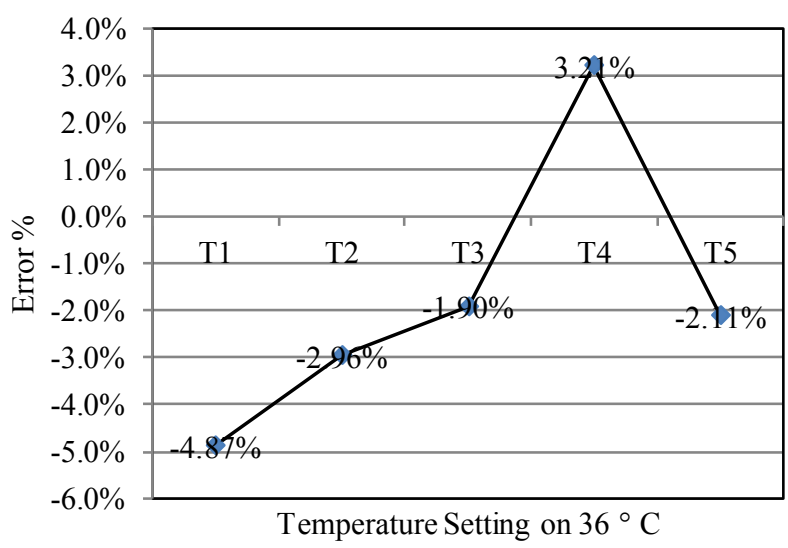

Fig. 14. Error measurement on temperature setting $36 \mathrm{oC}$

e. The measurement results of the difference between the module and INCU II at a temperature setting of $36^{\circ} \mathrm{C}$

The average result of the difference or error between the module and INCU II at the temperature measurement T1 to T5 $36^{\circ} \mathrm{C}$ temperature setting is $+-0.63{ }^{\circ} \mathrm{C}$ (Fig. 15).

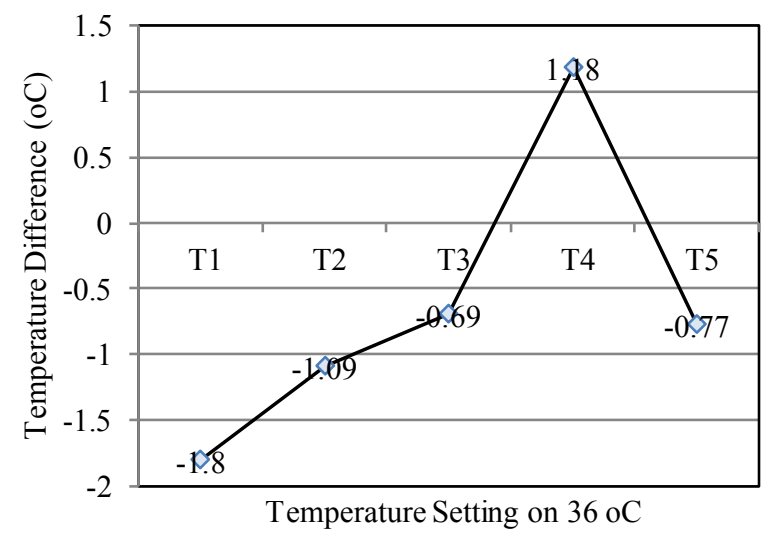

Fig. 15. The temperature difference between design and calibrator

f. Mattress error $\%$ measurement results at a temperature setting $36^{\circ} \mathrm{C}$

According to the measurement results of the comparison between modules and standard devices or INCU II $36 \mathrm{C}$ Temperature settings at the temperature of the mat the error results obtained $-7.39 \%$ percent. As for the difference or error between the module and INCU II on the measurement of the $36^{\circ} \mathrm{C}$ mat temperature, the temperature setting is $+-2.63^{\circ} \mathrm{C}$ (Fig.16).

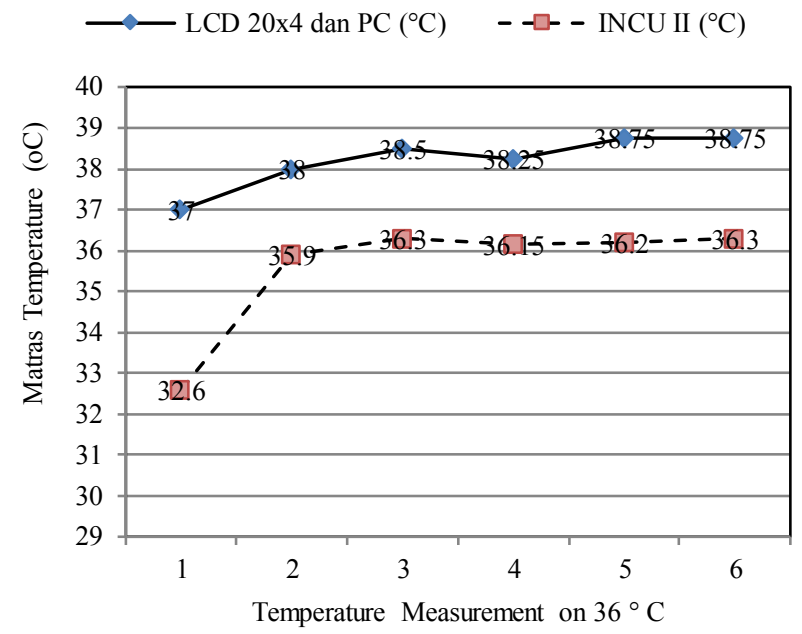

Fig. 16. Temperature measurement for mattress

\section{5) Error value DHT22}

a) Measurement humidity setting $34^{\circ} \mathrm{C}$

According to the measurement results of the comparison between modules and standard devices or INCU II temperature regulation $34^{\circ} \mathrm{C}$ on the humidity sensor, the error results obtained $-24.80 \%$. As for the difference or error between the module and INCU II is + - 10.53 (Fig. 17).

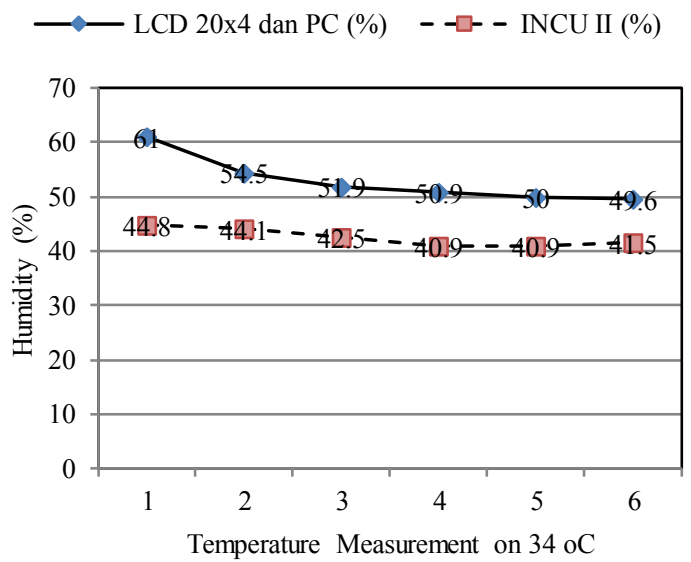

Fig. 17. Humidity measurement

b) Measurement humidity setting $36^{\circ} \mathrm{C}$

According to the measurement results of the comparison between modules and standard tools or INCU II temperature regulation $36 \mathrm{C}$ on the humidity sensor, the error results 
obtained $19.49 \%$ percent. As for the difference or error between the module and INCU II is +-11.22 (Fig.18).

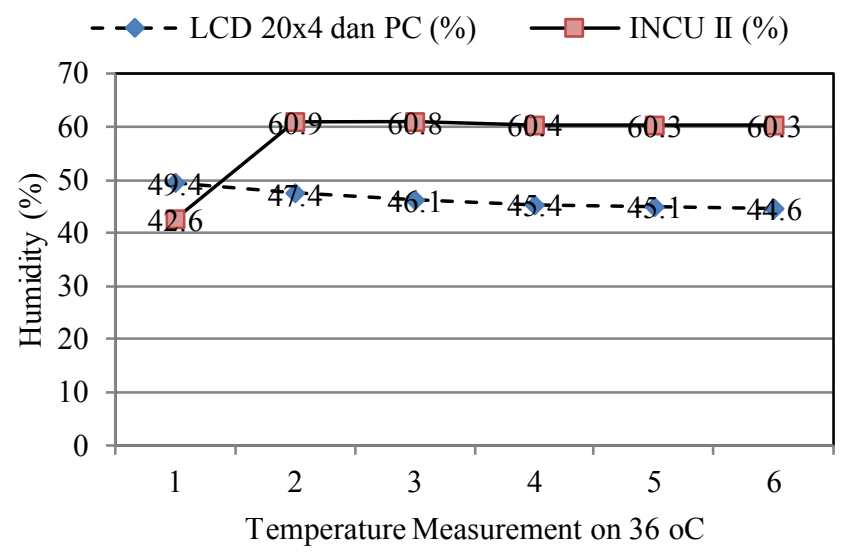

Fig. 18. Cross variable between temperature and humidity condition

\section{DISCUSSION}

After conducting research, collecting data on modules with standard tools using INCU II obtained the results of the analysis of temperature sensor readings and humidity sensors that the biggest percent error results on DS18B20 was $-4.87 \%$, for Thermocouple sensors obtained errors of $-7.39 \%$ and humidity sensors obtained errors $-24.80 \%$.

\section{CONCLUSION}

Based on the study, the purpose of the design is to design a device to calibrate the incubator baby. The calibration data can be displayed on a 4 x 20 LCD and a Delphi application using a computer. A Bluetooth connection was used to connect between the microcontroller and the computer. The error resulted in DS18B20 was $-4.87 \%$, for Thermocouple sensors obtained errors of $-7.39 \%$ and humidity sensors obtained errors $-24.80 \%$. From the results of the research, it was suggested to make a box with a smaller size to facilitate data retrieval when compared with standard gold/comparison tools. Data collection modules should be done simultaneously using a comparison tool on the same Baby Incubator in the shortest time interval and as much data collection as possible.

\section{REFERENCES}

[1] Permenkes 65 tahun, "Berita Negara," Menteri Kesehat. Republik Indones. Peratur. Menteri Kesehat. Republik Indones., vol. Nomor 65, no. 879 , pp. 2004-2006, 2015.

[2] The WHO Reproductive Health Library, "WHO recommendation on provision of care in a thermo-neutral environment for newborns cannot be given Kangaroo mother care," 2015. .

[3] G. T. Sen and M. Yuksekkaya, "Desing and Test of an Incubator Analyzer," ISMSIT 2018 - 2nd Int. Symp. Multidiscip. Stud. Innov. Technol. Proc., pp. 2-6, 2018.

[4] A. A. of Pediatrics, PERINATAL CARE Guidelines. 2012.

[5] M. Shaib, M. Rashid, L. Hamawy, M. Arnout, I. E. Majzoub, and A. J. Zaylaa, "Advanced portable preterm baby incubator," in 2017 Fourth
International Conference on Advances in Biomedical Engineering (ICABME), 2017, pp. 1-4.

[6] H. Mittal, L. Mathew, and A. Gupta, "Design and Development of an Infant Incubator for Controlling Multiple Parameters," Int. J. Emerg. Trends Electr. Electron., vol. 11, no. 5, pp. 2320-9569, 2015.

[7] L. S. Rizka Nur Uswatun Nadziroh, Endang Dian Setiningsih, "Incubator Analyzer Portabel Tampil PC Via Bluetooth (Sensor Kelembapan, Sensor Kebisingan dan Sensor Aliran Udara)." 2018.

[8] S. T. Imro'ah Dyah Sulistya, Syaifudin, "Incubator Analyzer Portable Dilengkapi dengan Pengiriman Data Melalui Bluetooth Tampil Android," J. Teknokes, Vol. 12, No. 2, 2018.

[9] A. A. Charisa, B. Utomo, and S. Syaifudin, "Incubator Analyzer Portabel Berbasis Pemrograman Visual Dilengkapi Penyimpanan ke Sd Card," J. Teknokes, vol. 12, no. 2, pp. 29-35, 2019.

[10] D. P. Ramya and A. Hussain, "A Light Weight Secured and Efficient Health Monitoring System Implemented Over IOT Based Networks," Plos, Vol 20, no. 6, pp. 1806-1809, 2019.

[11] J. Islam et al., "Design and Development of Microcontroller Based Wireless Humidity Monitor,", IOSR Journal of Electrical and Electronics Engineering, vol. 13, no. 2, pp. 41-46, 2018.

[12] M. Hulea, G. Mois, S. Folea, L. Miclea, and V. Biscu, "Wi-sensors: A low power Wi-Fi solution for temperature and humidity measurement," IECON Proc. (Industrial Electron. Conf., pp. 4011-4015, 2013. 